\title{
Evidence against GABA Release from Glutamatergic Mossy Fiber Terminals in the Developing Hippocampus
}

\author{
Motokazu Uchigashima, ${ }^{1}$ Masahiro Fukaya, ${ }^{1}$ Masahiko Watanabe, ${ }^{1}$ and Haruyuki Kamiya ${ }^{2}$ \\ Departments of ${ }^{1}$ Anatomy and ${ }^{2}$ Neurobiology, Hokkaido University School of Medicine, Sapporo 060-8638, Japan
}

\begin{abstract}
Hippocampal mossy fibers of young rodents have been reported to corelease inhibitory neurotransmitter GABA in addition to excitatory transmitter glutamate. In this study, we aimed at re-evaluating this corelease hypothesis of both inhibitory and excitatory transmitters in the hippocampus. Electrophysiological examination revealed that, in juvenile mice and rats of the two to 3 weeks old, stimulation at the granule cell layer of the dentate gyrus elicited monosynaptic GABAergic IPSCs in CA3 neurons in the presence of ionotropic glutamate receptor (iGluR) blockers, only when rather strong stimuli were given. The group II mGluR agonist $\left(2 S, 1^{\prime} R, 2^{\prime} R, 3^{\prime} R\right)-2-(2,3-$ dicarboxycyclo-propyl)glycine (DCG-IV), which selectively suppresses transmission at the mossy fiber-CA3 synapse, abolished almost all postsynaptic responses elicited by the weak stimuli, whereas those by strong stimuli were inhibited only slightly. In addition, the minimal stimulation elicited GABAergic IPSCs in neonatal mice of the first postnatal week, whereas these responses are not sensitive to DCG-IV. Immunohistochemical examination revealed that mossy fiber terminals expressed GABA and the GABA-synthesizing enzyme GAD67, although the expression levels were much weaker than those in the inhibitory interneurons. Notably, the expression levels of the vesicular GABA transporter were much lower than those of GABA and GAD67, and almost below detection threshold. These results suggest that mossy fiber synapses are purely glutamatergic and apparent monosynaptic IPSCs so far reported are evoked by costimulation of inhibitory interneurons, at least in young mice and rats. Hippocampal mossy fiber terminals synthesize and store GABA, but have limited ability in vesicular release for GABA in the developing rodents.
\end{abstract}

Key words: hippocampus; mossy fiber; corelease; GABA; GAD; VGAT

\section{Introduction}

A single subset of synapses usually releases a single class of fast neurotransmitter. This "single transmitter rule" was challenged by the findings that synapses in the spinal cord (Jonas et al., 1998) and brainstem (Nabekura et al., 2004) corelease GABA and glycine, both inhibitory neurotransmitters, at a certain stage of development. In the hippocampus, an intriguing hypothesis has been proposed that GABA, in addition to glutamate, is released from the mossy fiber terminals in the CA3 region of guinea pigs (Walker et al., 2001) and rats (Gutièrrez, 2000, 2002; Gutièrrez and Heinemann 2001; Gutièrrez et al., 2003) (for review, see Gutièrrez, 2005). This corelease hypothesis is of particular interest in several aspects. First, GABA releasing properties are tightly regulated by developmental time courses. In the rat hippocampus, it has been reported that GABAergic phenotypes of the dentate gyrus granule cells are observed until postnatal day 22 (P22)$\mathrm{P} 24$, and disappear suddenly thereafter (Gutièrrez et al., 2003). Second, GABAergic phenotypes at the mossy fiber synapses reappear after seizure in adult rats (Gutièrrez, 2000, 2002; Gutièrrez

Received Feb. 15, 2007; revised June 13, 2007; accepted June 13, 2007.

This work was supported by Grants-in-Aid for Science Research from the Ministry of Education, Science, Sports, Culture and Technology of Japan (M.W., H.K.), and by grants from Ichiro Kanehara Foundation and from Novartis Foundation for the Promotion of Science (H.K.). We are grateful to Dr. Toshiya Manabe for critical reading of this manuscript.

Correspondence should be addressed to Haruyuki Kamiya, Department of Neurobiology, Hokkaido University School of Medicine, Sapporo 060-8638, Japan. E-mail: kamiya@med.hokudai.ac.jp.

DOI:10.1523/JNEUROSCI.0702-07.2007

Copyright $\odot 2007$ Society for Neuroscience $\quad$ 0270-6474/07/278088-13\$15.00/0 and Heinemann 2001; Gutièrrez et al., 2003). In other words, GABA releasing properties from mossy fiber terminals are switched off according to development and switched on by induction of a hyperexcitable state. Switching of neurotransmitter modality is a novel mechanism of synaptic plasticity, and therefore intensive attention has been paid to the mechanisms underlying developmental and activity-dependent switch of GABAreleasing machinery at this synapse. In addition, corelease of GABA and glutamate at developing mossy fiber synapses is notable not only for neurobiological peculiarity, but also for seeking the mechanism of developmental refinement of the neural network, because GABA is involved in the development of the mossy fiber network (Represa and Ben-Ari, 2005), and functional $\mathrm{GABA}_{\mathrm{A}}$ (Ruiz et al., 2003; Alle and Geiger, 2007) and $\mathrm{GABA}_{\mathrm{B}}$ receptors (Vogt and Nicoll, 1999) are expressed on the presynaptic terminals.

In this study, we focused on assessing the exact cellular mechanism underlying corelease of GABA and glutamate at the hippocampal mossy fiber synapses. For this purpose, detailed experimental conditions to evoke monosynaptic IPSCs were re-examined closely using whole-cell recordings in mouse hippocampal slices while paying much attention to selectively stimulate solely the mossy fiber pathway, because it was noticed that rather strong stimulus or inadequate positioning of the stimulating electrode readily recruit additional interneurons and/or their axons in the hilus. Moreover, to obtain detailed information on the molecular machinery critical for GABA synthesis and 
vesicular release, we also performed histochemical analyses for the expression and distribution of GAD, GABA, and vesicular $\gamma$-aminobutylic acid transporter (VGAT) in the mossy fiber terminals. Against the hypothesis, the present study provides experimental evidence that mossy fibers are purely glutamatergic, not only in the adult brain, but also during the development stage.

\section{Materials and Methods}

Animals and slice preparations. C57BL/6J mice and Wistar rats were used in the present study, and treated according to the guidelines for the care and use of laboratory animals of Hokkaido University School of Medicine. Transverse hippocampal slices of $400 \mu \mathrm{m}$ thick were prepared from 4- to 20-d-old mice and rats as described previously (Kamiya et al., 2002). In this study, we denoted mice of age P14-P20 as "juvenile" mice, and those of age P4-P6 as "neonatal" mice. Animals were anesthetized with ether and the brains were dissected out in an ice-cold sucrose solution containing (in mM) $40 \mathrm{NaCl}, 25 \mathrm{NaHCO}_{3}, 10$ glucose, 150 sucrose, $4 \mathrm{KCl}$, $1.25 \mathrm{NaH}_{2} \mathrm{PO}_{4}, 0.5 \mathrm{CaCl}_{2}$, and $7 \mathrm{MgCl}_{2}$ (Geiger et al., 2002). Transverse slices were cut using a DTK-1000 microslicer (Dosaka-EM, Kyoto, Japan) and incubated for approximately $1 \mathrm{~h}$ in the above solution. Then, sucrose-containing solution was replaced with the physiological saline containing (in mM) $127 \mathrm{NaCl}, 1.5 \mathrm{KCl}, 1.2 \mathrm{KH}_{2} \mathrm{PO}_{4}, 26 \mathrm{NaHCO}_{3}, 10$ glucose, $2.4 \mathrm{CaCl}_{2}$, and $1.3 \mathrm{MgCl}_{2}$, and they were kept in an interfacetype chamber saturated with $95 \% \mathrm{O}_{2}$ and $5 \% \mathrm{CO}_{2}$.

Whole-cell recordings. Neurons in the pyramidal cell layer of $\mathrm{CA}_{\mathrm{b}}$ region were visually identified using an upright microscope equipped with $40 \times$ objective and differential interference contrast optics (BX-50 WI; Olympus, Tokyo, Japan). Whole-cell patch-clamp recordings were performed using an Axopatch 1D amplifier (Molecular Devices, Sunnyvale, CA) in voltage-clamp mode, usually at $-80 \mathrm{mV}$. Patch pipettes of 4-8 $\mathrm{M} \Omega$ were pulled from borosilicate glass (Harvard Apparatus, Edenbridge, UK) and filled with an internal solution containing (in mM) 135 $\mathrm{CsCl}, 8 \mathrm{NaCl}, 10$ HEPES, 2 EGTA, $0.2 \mathrm{MgCl}_{2}, 5$ lidocaine $N$-ethyl bromide quaternary salt (QX314), 2 MgATP, and 0.3 GTP, pH 7.2. Series resistance was monitored throughout the experiment, and the data were not included if the resistance changed $>10 \%$ of the initial value. Electrical stimuli of $100 \mu$ s duration were delivered through a concentric bipolar stimulating electrode at the granular cell layer of dentate gyrus or at the stratum lucidum of CA3 region using an ISO-Flex isolation unit (AMPI, Jerusalem, Israel). Synaptic responses were usually evoked every 10 s. In experiments shown in Figures 1, 3, 4, and supplemental Figures 1, 3,4 , and 5 (available at www.jneurosci.org as supplemental material), stimuli with two kinds of intensity (weak and strong) were applied alternately through the same stimulating electrode every $10 \mathrm{~s}$. We denoted this stimulating protocol as "two-intensity protocol" in this study, which allowed concurrent monitoring of the effect of stimulus intensity in the same slice preparations and in the same recording conditions. Intensity of strong stimulus was set to evoke PSCs of several nanoamperes at -80 $\mathrm{mV}$, which is comparable with that used for evoking "monosynaptic" IPSCs in a previous study (Walker et al., 2001). Intensity of the weak stimulus was set to evoke PSCs in the range of hundreds of picoamperes. In the experiments in Figure 5, minimal stimulation was applied to evoke unitary responses of putative "single" mossy fiber stimulation (Safiulina et al., 2006). For this purpose, stimulus intensity was adjusted just above the threshold intensity to evoke detectable responses. In another set of experiments shown in supplemental Figures 8 and 9 (available at www. jneurosci.org as supplemental material), L-glutamate $(100 \mathrm{~mm}, \mathrm{pH}$ was adjusted to 8.0) was applied through patch pipette by giving short pulses of pressure (0.3-0.4 bar, 5-10 ms duration) using PV830 pneumatic Picopump (WPI, Sarasota, FL). The pipette was positioned to the molecular cell layer of dentate gyrus with the aid of visualization under microscope. Signals were filtered at $1 \mathrm{kHz}$, and were digitized at $10 \mathrm{kHz}$ with a DIGIDATA 1322A interface with 16-bit resolution (Molecular Devices). The Data were fed into a personal computer and analyzed off-line using pClamp 9.0 software (Molecular Devices). All values are expressed as mean \pm SEM. Statistical analysis was performed using Student's $t$ test, and $p<0.05$ was accepted for statistical significance.

Chemicals. Drugs used in the electrophysiological experiments were as follows: 6-cyano-7-nitroquinoxaline-2,3-dione (CNQX), 2,3-dioxo6-nitro-1,2,3,4-tetrahydrobenzo quinoxaline-7-sulfonamide (NBQX), D-(-)-2-amino-5-phosphonopentanoic acid (D-AP-5), and $\left(2 S, 1^{\prime} R, 2^{\prime}\right.$ $R, 3^{\prime} R$ )-2-(2,3-dicarboxycyclo-propyl)glycine (DCG-IV) from Tocris Cookson (Bristol, UK). QX314 was purchased from Sigma (St. Louis, $\mathrm{MO})$.

In situ hybridization. Antisense oligonucleotide probes were synthesized; probe sequences are $5^{\prime}$-gtaggccagcacgaacatgccctgaatggcatttgtcacgttcc- $3^{\prime}$ and $5^{\prime}$-accetcaaggtcaagtttccaagcctgcgaactttccctcgagtga- $3^{\prime}$ for VGAT (409-453 and 1572-1617 nucleotide residues, GenBank accession number NM009508), 5'-tcccgcgttcgaggaggttgcaggcgaaggagtggaagatgccat-3' for GAD67 (234-288, GenBank accession number NM008077), and 5' -atcttcagatccgaaggaccaaaagccggagccaggagacgccat-3' for GAD65 (353-397, GenBank accession number NM008078). They were radiolabeled with $\left[{ }^{33} \mathrm{P}\right] \mathrm{dATP}$ using terminal deoxyribonucleotidyl transferase (Invitrogen, Carlsbad, CA).

Under deep pentobarbital anesthesia (100 mg/kg of body weight, i.p.), brains were freshly removed from the skull and frozen in powdered dry ice for in situ hybridization. Frozen sections were prepared on a cryostat (20 $\mu \mathrm{m}$ in thickness; CM1900; Leica, Nussloch, Germany) and mounted on silane-coated glass slides (Muto-Glass, Tokyo, Japan). Fresh frozen sections were treated at room temperature with the following incubations: fixation with $4 \%$ paraformaldehyde in phosphate buffer (PB) for $10 \mathrm{~min}, 2 \mathrm{mg} / \mathrm{ml}$ glycine-PBS, pH 7.2, for $10 \mathrm{~min}$, and acetylation with $0.25 \%$ acetic anhydride in $0.1 \mathrm{~m}$ triethanolamine- $\mathrm{HCl}, \mathrm{pH} 8.0$, for 10 min. Sections were prehybridization for $1 \mathrm{~h}$ in a buffer containing $50 \%$ formamide, $50 \mathrm{~mm}$ Tris- $\mathrm{HCl}$, $\mathrm{pH}$ 7.5, 0.02\% Ficoll, $0.02 \%$ polyvinylpyrrolidone, $0.02 \%$ bovine serum albumin, $0.6 \mathrm{M} \mathrm{NaCl}, 0.25 \%$ SDS, 200 $\mu \mathrm{g} / \mathrm{ml}$ tRNA, and $1 \mathrm{~mm}$ EDTA. Hybridization was performed at $42^{\circ} \mathrm{C}$ for $12 \mathrm{~h}$ in the prehybridization buffer supplemented with $10,000 \mathrm{cpm} / \mu \mathrm{l}$ of $\left[{ }^{33} \mathrm{P}\right] \mathrm{dATP}-\mathrm{labeled}$ probes and $10 \%$ dextran sulfate. Slides were washed twice at $55^{\circ} \mathrm{C}$ for $40 \mathrm{~min}$ in $0.1 \times$ SSC containing $0.1 \%$ sarcosyl. Sections were exposed to BioMax film (Kodak, Rochester, NY) and to nuclear track emulsion.

Antibody. We used primary antibodies raised against the following molecules (species immunized): mouse calbindin (rabbit and goat) (Nakagawa et al., 1996; Miura et al., 2006), rat and mouse vesicular glutamate transporter 1 (VGluT1; guinea pig and goat) (Miyazaki et al., 2003; Miura et al., 2006), mouse VGAT (rabbit, guinea pig, and goat) (Miyazaki et al., 2003; Miura et al., 2006), mouse GAD67/65 (Yamada et al., 2001) (rabbit), and GABA (rabbit; catalog \#A2052; Sigma). For specificity control, VGAT and GAD antibodies were preabsorbed by overnight incubation with $50-100 \mu \mathrm{g} / \mathrm{ml}$ of antigens (Yamada et al., 2001; Miyazaki et al., 2003)

Immunohistochemistry. For immunohistochemistry, anesthetized mice were fixed transcardially with either $4 \%$ paraformaldehyde in $0.1 \mathrm{M}$ sodium $\mathrm{PB}, \mathrm{pH} 7.2$, or $4 \%$ paraformaldehyde/0.1\% glutaraldehyde in $\mathrm{PB}$ (for GABA immunofluorescence only), and microslicer $(50 \mu \mathrm{m})$ or paraffin $(4 \mu \mathrm{m})$ sections were prepared. All immunohistochemical incubations were done at room temperature in a free-floating state. For immunofluorescence, microslicer sections were incubated with $10 \%$ normal donkey serum for $20 \mathrm{~min}$, a mixture of primary antibodies overnight (1 $\mu \mathrm{g} / \mathrm{ml}$ ), and a mixture of Alexa 488-, Cy3-, and Cy5-labeled speciesspecific secondary antibodies for $2 \mathrm{~h}$ at a dilution of 1:200 (Invitrogen; Jackson ImmunoResearch, West Grove, PA). PBS, pH 7.4, containing $0.1 \%$ Tween 20 was used for diluent of antibodies and washing buffer. For immunoperoxidase, paraffin sections were incubated with $10 \%$ normal donkey serum for $30 \mathrm{~min}$, primary antibodies $(1 \mu \mathrm{g} / \mathrm{ml})$ overnight, biotinylated secondary antibody for $2 \mathrm{~h}$, and streptavidin-peroxidase complex for 30 min using a Histofine SAB-PO(R) kit (Nichirei, Tokyo, Japan), followed by visualization with $3,3^{\prime}$-diaminobenzidine. Images were taken with a light microscope (AX-70; Olympus) equipped with a digital camera (DP70; Olympus) or with a confocal laser scanning microscope (FV1000; Olympus).

Western blotting. Adult mouse brains were homogenized using a Potter homogenizer with 15 strokes at $1000 \mathrm{rpm}$ in 10 volumes of ice-cold homogenizer buffer containing $0.32 \mathrm{~m}$ sucrose, 1 mм EDTA, 1 mм EGTA, $10 \mathrm{~mm}$ Tris-HCl, pH 7.2, and $0.4 \mathrm{~mm}$ phenylmethylsulfonyl fluoride. The protein concentration was determined by the Lowry's method. Proteins 
(10 $\mu \mathrm{g} /$ lane) were separated by SDS-PAGE, and electroblotted onto nitrocellulose membranes (BioTraceNT; PALL, Ann Arbor, MI). After blocking with $5 \%$ skimmed milk for $1 \mathrm{~h}$, membranes were incubated for $2 \mathrm{~h}$ with VGAT [goat (see Fig. 7a); rabbit and guinea pig (data not shown)] or GAT67/65 [rabbit (see Fig. 7a)] antibody $(1 \mu \mathrm{g} / \mathrm{ml})$. Tris-buffered saline, $\mathrm{pH} 7.5$, containing $0.1 \%$ Tween 20 was used for diluent and washing buffer. Immunoreaction was visualized with the ECL chemiluminescence detection system (Amersham Biosciences, Arlington Heights, IL).

\section{Results}

Monosynaptic GABAergic responses are elicited by stimulation of the granule cell layer in juvenile mice

So far, the strongest evidence for corelease of GABA and glutamate from the hippocampal mossy fiber terminals is that monosynaptic GABAergic IPSCs were evoked by stimulation of the granule cell layer of the dentate gyrus in the presence of glutamate receptor blockers, in guinea pigs (Walker et al., 2001) and young rats (Gutièrrez et al., 2003). First, we tested whether similar monosynaptic GABAergic responses were recorded in juvenile mice at P14-P20. Whole-cell recordings were obtained from CA3 neurons using patch pipettes containing CsCl-based solution, and mossy fibers were stimulated at the granule cell layer of the dentate gyrus and the resultant PSCs were recorded at -80 $\mathrm{mV}$. In these conditions, glutamatergic EPSCs and GABAergic IPSCs are both recorded as inward current responses. In line with previous studies, relatively strong stimuli to the granular cell layer elicited monosynaptic IPSC in the presence of AMPA and NMDA receptor blockers, 10 $\mu \mathrm{M}$ CNQX and $25 \mu \mathrm{M}$ D-AP-5, respectively, and the residual PSCs were blocked by additional application of $\mathrm{GABA}_{\mathrm{A}}$ receptor antagonist $100 \mu \mathrm{M}$ picrotoxin (Fig. $1 A)$. In other experiments, however, application of glutamate receptor antagonists abolished all synaptic responses (Fig. $1 B)$, particularly when relatively weaker stimuli were applied.

\section{Two-intensity experiment reveals stimulus intensity dependency for "monosynaptic" GABAergic signaling} One possibility for the experimental fluctuation is that stimulation was not selective enough in some experiments to solely stimulate mossy fibers. A weak stimulus is expected to activate granule cells and their axon mossy fibers selectively, whereas a strong stimulus might costimulate inhibitory interneurons in the CA3 region or their axon collaterals and elicit monosynaptic IPSC by axon reflex mechanism. To test this possibility, we performed two-intensity stimulus experiments
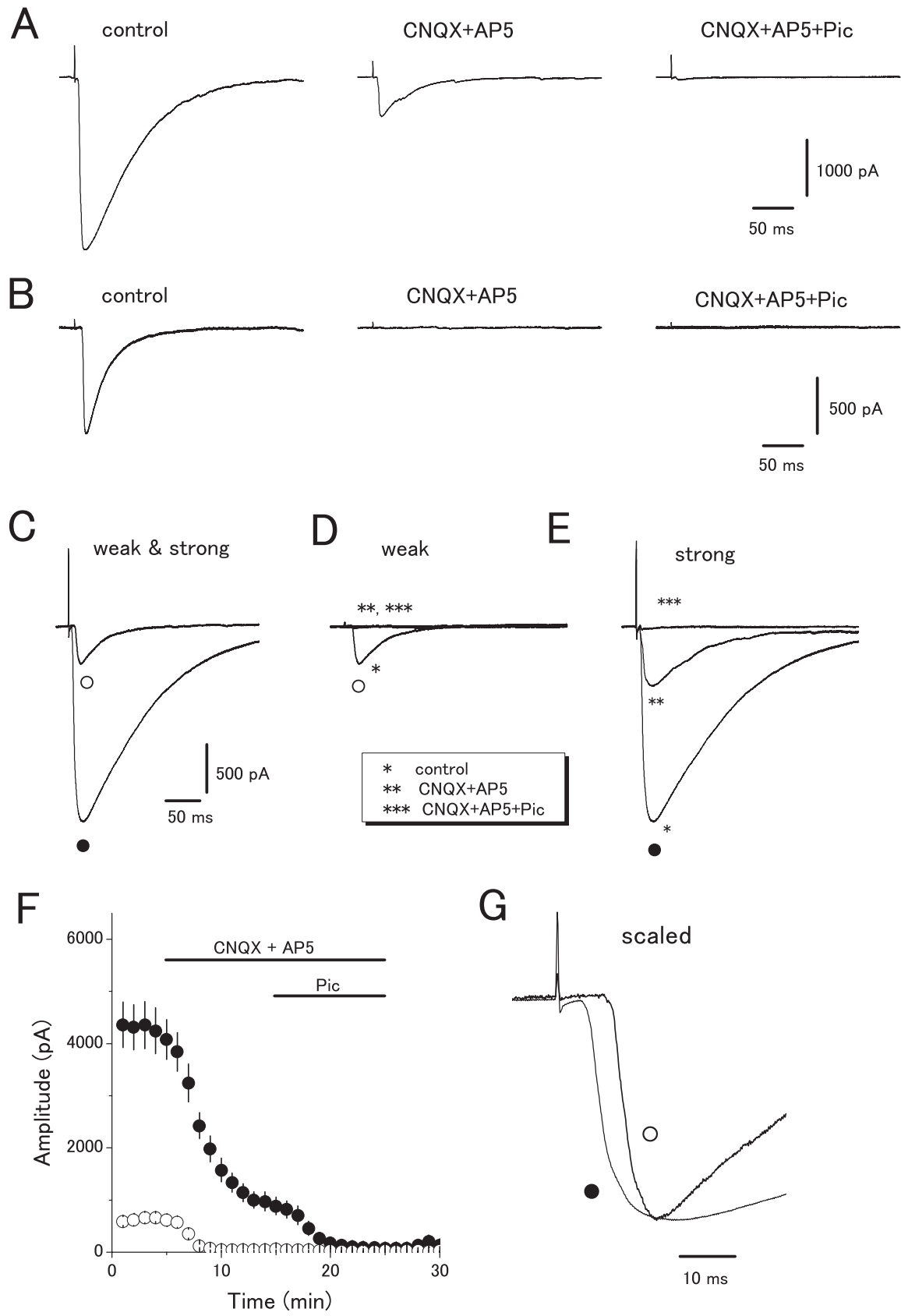

Figure 1. Stimulation of the granule cell layer, which originates the mossy fiber pathway, evokes GABAergic synaptic responses resistant to iGluR blockers in juvenile mice (P14-P20). A, Representative records of PSCs elicited by rather strong stimulation ( $800 \mu \mathrm{A}, 100 \mu \mathrm{s}$ in this experiment). Note that substantial responses remained after application of $10 \mu \mathrm{M}$ CNQX and $25 \mu \mathrm{m} \mathrm{D}-\mathrm{AP}-5$, and the residual responses were completely abolished by additional application of $100 \mu \mathrm{m}$ picrotoxin (Pic). B, PSCS elicited by relatively weak stimulation ( $150 \mu \mathrm{A}, 100 \mu \mathrm{s}$ in this experiment). Application of CNQX and D-AP-5 abolished the responses almost completely. Traces are the average of five consecutive synaptic responses evoked at $0.1 \mathrm{~Hz}$. C, The PSCs were evoked alternately by weak (open circles) and strong stimuli (closed circles) through the same stimulating electrode (see Materials and Methods, Two-intensity protocol). $\boldsymbol{D}, \boldsymbol{E}$, Representative traces are those recorded before $\left({ }^{*}\right)$ and $10 \mathrm{~min}$ after application of 10 $\mu \mathrm{M}$ CNQX and $25 \mu \mathrm{M}$ D-AP-5 $\left(^{* *}\right)$, and additional application of $100 \mu \mathrm{m}$ picrotoxin $\left(^{* * *}\right)$. $\boldsymbol{F}$, Summary of time courses of the amplitudes of PSCS. G, To compare the difference in latency of the evoked responses, the initial phase of the PSCs was expanded along the time axis and the amplitudes were scaled to normalize the peak amplitudes of the traces shown in C. PSCs evoked by strong stimuli (closed circles) displayed significantly shorter latencies than those evoked by weak stimuli (open circles), suggesting stimulation at the position closer to the recording neuron.

(see Materials and Methods). Weak and strong stimuli were applied alternately through the same stimulating electrode inserted into the granule cell layer (Fig. 1C). In this experiment, responses evoked by weak stimulation were almost completely abolished by application of CNQX and AP-5 (Fig. 1D), whereas those by 
strong stimulation remained substantially after application of these glutamate receptor antagonists, and the residual PSC was blocked by additional application of picrotoxin (Fig. 1E). On average, amplitudes of strong stimulus-evoked PSCs were reduced from $4080 \pm 380 \mathrm{pA}$ to $818 \pm 169 \mathrm{pA}$ (mean \pm SEM; $n=$ 9) by application of CNQX and D-AP-5, whereas those of weak stimulus PSCs were almost abolished by these blockers (from $617 \pm 116 \mathrm{pA}$ to $43 \pm 5 \mathrm{pA}$ ) (Fig. $1 F$ ). The relative magnitude of block by CNQX and D-AP-5 was significantly larger for responses elicited by a weak stimulus than those by a strong stimulus $(p<$ 0.01). In another set of experiments, we used $10 \mu \mathrm{M}$ gabazine (SR95531), a selective blocker of $\mathrm{GABA}_{\mathrm{A}}$ receptors, and the results were quite similar to those obtained using picrotoxin (supplemental Fig. 1, available at www.jneurosci.org as supplemental material). We also noted different latencies between strong and weak stimulus-induced PSCs. When comparing the latency of evoked responses (Fig. 1G), the latency after a strong stimulus was always shorter than that after a weak stimulus in every twointensity experiment $(4.5 \pm 0.3 \mathrm{~ms}$ for strong stimulus; $8.5 \pm 0.7$ ms for weak stimulus; $p<0.001$ ), suggesting that strong stimuli activate axons at closer position from the recording site than weak stimuli do.

To analyze the latency difference in more detail, we changed the stimulus intensity systematically (Fig. $2 \mathrm{~A}$ ). As expected for current spread by a stronger stimulus activating axons near the recorded cell, the latency became shorter as the stimulus strength increased (Fig. 2 B). This also holds for IPSCs evoked by strong stimulation in the presence of nonspecific iGluR blocker kynurenic acid (Fig. 2C,D). The amplitudes of PSCs recorded in the absence and the presence of kynurenic acid changed according to the stimulus strength, but the relationships were different between two groups (Fig. 2E) (1-6 V, 1 V steps). Furthermore, the latencies were consistently different at various stimulus strengths $(p<0.05)$ (Fig. $2 F)$. Longer latencies in the presence of kynurenic acid might be attributable to the distal location of the action-potential generating point for IPSCs (possibly in the hilus) from the stimulating electrode in the granule cell layer. For eliciting IPSCs, it would take a longer time for attenuated stimulation currents at the site distal from the stimulating electrode to reach the threshold potential.

These results strongly suggest that additional circuits were also recruited by strong stimuli and the apparent monosynaptic IPSCs were originated from different inputs other than mossy fibers.

\section{Stimulation at CA3 stratum lucidum readily elicits monosynaptic GABAergic responses}

If apparent monosynaptic GABAergic IPSCs were caused by activation of interneurons that reside around the granule cell layer and project axons both to the dentate gyrus and to CA3 pyramidal cells, they could be evoked more readily when axons projecting to CA3 pyramidal cells are directly stimulated. When stimulus was given to the stratum lucidum of the CA3 region, substantial picrotoxin-sensitive IPSCs were left after application of CNQX and AP-5, even when stimulus intensity was lowered to the levels that evoked CNQX and AP-5-sensitive responses only by stimulation of the granule cell layer (Figs. $1 D$, supplemental Fig. $2 A, B$, available at www.jneurosci.org as supplemental material). On average, amplitude of PSCs was reduced from $595 \pm 35$ pA to $359 \pm 46 \mathrm{pA}(n=7)$ by application of CNQX and D-AP-5 (supplemental Fig. 2C, available at www.jneurosci.org as supplemental material). This result is also consistent with the notion that monosynaptic GABAergic IPSCs are elicited because of co-
A

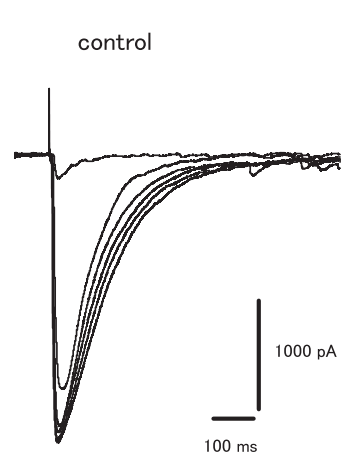

B

control
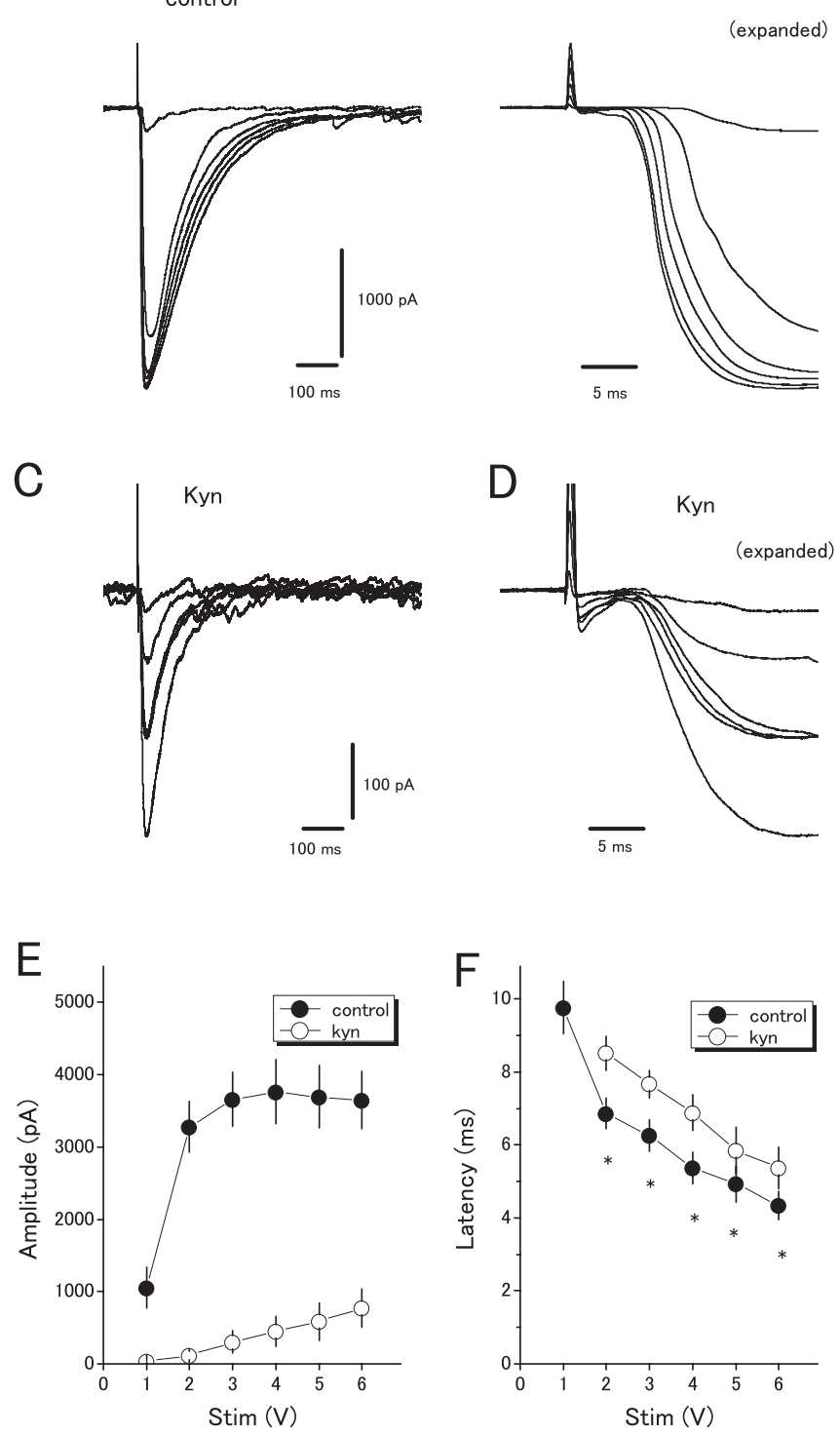

Figure 2. Relationships between stimulus intensity and latency of PSCS. $A$, PSCs evoked by a variety of stimulus strengths (1-6V, 1 V steps) were superimposed. $B$, Initial phase of the PSCs was expanded along the time axis to demonstrate clear dependency of the latencies on the stimulus strength. C, D, IPSCS were recorded in the presence of $5 \mathrm{~mm}$ kynurenic acid (Kyn), a nonselective iGluR blocker, and shown in $\boldsymbol{A}$ and $\boldsymbol{B} . \boldsymbol{E}, \boldsymbol{F}$, Amplitudes $(\boldsymbol{E})$ and latencies $(\boldsymbol{F})$ of PSCs in the absence (closed circles) and presence (open circles) of kynurenic acid were plotted against stimulus intensity. The two groups consistently have different latencies for a variety of stimulus strengths $\left({ }^{*} p<0.05\right)$.

stimulation of inhibitory interneurons projecting to CA3 pyramidal cells.

\section{Strong responses are less-sensitive to DCG-IV than weak responses}

Above results suggest that strong stimulus to the granule cell layer recruits the interneuron pathway in addition to the mossy fiber pathway and elicits IPSCs resistant to CNQX and AP-5. If this is the case, PSCs activated by strong stimulus may exhibit differential sensitivity to group II mGluR agonist DCG-IV from those evoked by weak stimulus, because DCG-IV selectively suppresses mossy fiber transmission (Kamiya et al., 1996; Yokoi et al., 1996). Then we examined this possibility using two-intensity protocol 
similar to the experiments in Figure $1 C-G$ (Fig. 3A). Application of $1 \mu \mathrm{M}$ DCG-IV almost completely abolished the responses evoked by weak stimulation of the granule cell layer of dentate gyrus (Fig. $3 B$ ) (from $278 \pm 28$ pA to $17 \pm 4$ pA; $n=9)($ Fig. $3 D)$, whereas responses evoked by strong stimulation were suppressed by DCG-IV only partially (Fig. 3C) (from $3241 \pm 431 \mathrm{pA}$ to $2551 \pm 364$ pA; $n=9$ ) (Fig. $3 D$ ). This remaining DCG-IV-insensitive fraction was reduced greatly by CNQX and AP-5, and completely by further addition of picrotoxin, and therefore reflects monosynaptic or polysynaptic excitation or inhibition caused by pathways other than mossy fibers. The DCG-IV-insensitive, but CNQX and AP-5-sensitive component (Fig. 3C,D) is possibly attributable to direct stimulation of associational fibers and subsequent recruitment of polysynaptic activation of the recurrent excitatory network as well as the feedback inhibitory loop in the CA3 region. The latency after strong stimuli was always shorter than that after weak stimuli in every experiment $(9.5 \pm 0.7 \mathrm{~ms}$ for weak stimulus, $6.2 \pm 0.5 \mathrm{~ms}$ for strong stimulus; $p<0.001$ ) (Fig. 3E). We also performed two-intensity experiments in field potential recordings, and the stimulus intensitydependency of the DCG-IV effect was again evident in this series of experiments (supplemental Fig. 3, available at www. jneurosci.org as supplemental material). Thus, strong stimuli to the dentate gyrus activate not only the DCG-IV-sensitive mossy fiber-CA3 pathway, but also recruit the DCG-IV-insensitive inhibitory pathway to CA3 pyramidal cells.

\section{DCG-IV sensitivity is different between}

\section{mossy fiber EPSCs and apparent monosynaptic IPSCs}

To further confirm that apparent monosynaptic IPSCs originate from different inputs other than mossy fibers, we compared sensitivity of mossy fiber EPSCs and IPSCs recorded in the presence of iGluR blockers to DCG-IV. For this purpose, we again used two intensity protocols. Application of rather nonspecific iGluR blocker kynurenic acid at $5 \mathrm{~mm}$ abolished the responses to weak stimulus (Fig. 4A), but left substantial responses to strong stimulus, which were abolished by additional application of picrotoxin. DCG-IV at $1 \mu \mathrm{M}$ only weakly suppressed the kynurenic acid-resistant IPSCs (to $86 \pm 7 \%$ of control; $n=7$ ) (Fig. $4 B-D$ ). It should be noted that the effect of DCG-IV on IPSCs is somewhat overestimated, because the amplitudes of IPSCs continued to decrease before application of DCG-IV. In different experiments, responses by weak stimuli were strongly suppressed by the same concentration of DCG-IV (to $22 \pm 6 \%$ of control; $n=10$ ) (Fig. $4 E-H)$. The difference is statistically significant $(p<0.01)$. This result also suggests that monosynaptic GABAergic IPSCs do not reflect corelease of GABA from the mossy fiber terminals, but are possibly originated from inhibitory interneurons. We could not completely exclude the possibility that subpopulation of GABAergic fibers are strongly sensitive to DCG-IV, although such subpopulation, if any, represents only a small fraction of the whole population of mossy fibers.

\section{Similar results are obtained in rat slices}

In previous studies, iGluR blocker-resistant monosynaptic IPSCs were reported in rat or guinea pig hippocampal slices (Gutièrrez, 2000, 2002; Gutièrrez and Heinemann 2001; Gutièrrez et al., 2003; Walker et al., 2001). Our results in mice slices, therefore, may reflect species difference of the animals used for the experiments. Then, we repeated the same experiments in Figure 1 and Figure 4 in rat hippocampal slices. The results were quite similar to those obtained in mice (supplemental Figs. 4, 5, available at www.jneurosci.org as supplemental material), suggesting that species difference is not the cause of the different conclusions of this and the previous studies.

\section{Unitary GABAergic IPSCs in neonatal mice are sensitive to L-AP4, but not to DCG-IV}

Recently, it has been reported that "minimal stimulation" of the granule cell layer elicited monosynaptic GABAergic IPSCs in CA3 neurons of neonatal rat during the first postnatal week (Safiulina et al., 2006). Because these unitary IPSCs were suppressed by 

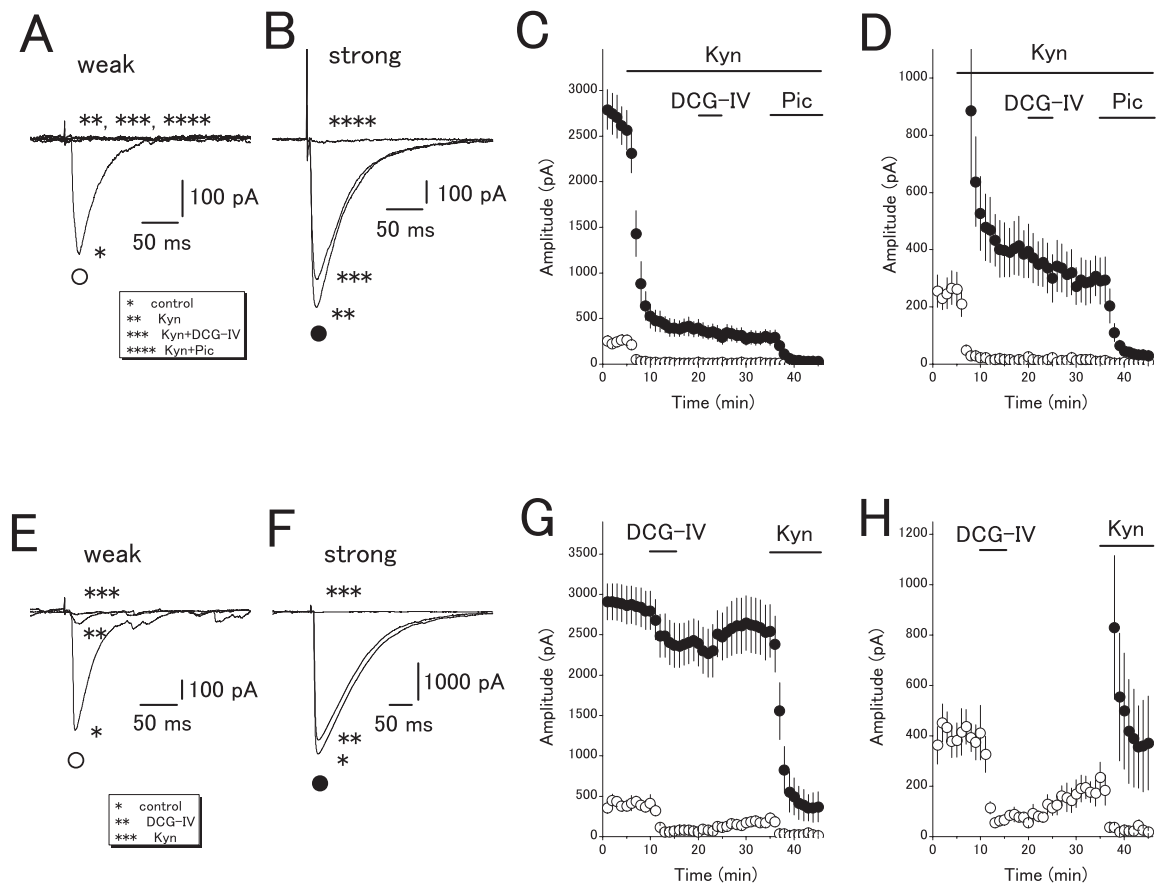

Figure 4. Comparison of DCG-IV sensitivity of monosynaptic IPSCs elicited by a strong stimulus and EPSCs evoked by a weak stimulus. $\boldsymbol{A}, \boldsymbol{B}$, Representative traces are those recorded before $\left({ }^{*}\right)$ and after application of $5 \mathrm{~mm}$ kynurenic acid $\left(\mathrm{Kyn} ;{ }^{* *}\right)$, and subsequent application of $1 \mu \mathrm{m}$ DCG-IV $\left({ }^{* * *}\right)$ and of $100 \mu \mathrm{m}$ picrotoxin (Pic; $\left.{ }^{* * *}\right)$. IPSCs recorded in kynurenic acid (B) were suppressed only weakly by DCG-IV. C, Summary of time courses of the amplitudes of PSCS. D, Same as in C, except for expanded vertical axis. $\boldsymbol{E}, \boldsymbol{F}$, Representative traces recorded before $\left({ }^{*}\right)$ and after application of $1 \mu \mathrm{m} \mathrm{DCG-IV}\left({ }^{* *}\right)$ and subsequent application of 5 mm kynurenic acid $\left.{ }^{* * *}\right)$. EPSCs evoked by weak stimulus $(\boldsymbol{E})$ were much more strongly suppressed by DCG-IV $(\boldsymbol{F})$. G, Summary of time courses of the amplitudes of PSCS. $\boldsymbol{H}$, Same as in $\boldsymbol{G}$, except for expanded vertical axis.

group III mGluR agonist L-AP-4, the authors suggested lowthreshold mossy fibers, which release only GABA are present in neonatal hippocampus, and these fibers undergo elimination after first postnatal week. We then tested this issue in neonatal mice of age P4-P6.

As reported in the rat, minimal stimulation of the granule cell layer in neonatal mice evoked GABAergic PSCs, which were insensitive to CNQX and D-AP-5, and blocked by picrotoxin (Fig. $5 A)$. Amplitudes of the unitary IPSCs were $41 \pm 9 \mathrm{pA}(n=5)$ (Fig. $5 B$ ), being comparable with the values obtained in neonatal rats (Safiulina et al., 2006). L-AP-4 at $10 \mu \mathrm{M}$ did suppress the unitary IPSCs (from $53 \pm 14 \mathrm{pA}$ to $31 \pm 8 \mathrm{pA} ; n=8$ ) (Fig. $5 C, D$ ). However, DCG-IV at $1 \mu \mathrm{M}$ did not significantly affect the unitary IPSCs (Fig. 5E). The amplitude before and after DCG-IV application was $49 \pm 7 \mathrm{pA}$ and $48 \pm 10 \mathrm{pA}$, respectively $(n=6)$ (Fig. $5 F$ ). Because mossy fiber transmission was equally suppressed by L-AP-4 and by DCG-IV, as revealed by calcium imaging of individual presynaptic terminals (Pelkey et al., 2006), and DCG-IV suppressed mossy fiber transmission even at these early postnatal stage (supplemental Fig. 6, available at www.jneurosci.org as supplemental material) (Marchal and Mulle, 2004), these results suggest that unitary IPSCs evoked by minimal stimulation of the granule cell layer in neonatal hippocampus are likely to be mediated by GABA release from low threshold interneurons different from mossy fibers. We could not exclude the possibility, however, that glutamate and GABA release from the mossy fibers is differentially regulated by DCG-IV and L-AP-4, as suggested for postseizure rat hippocampus (Treviňo et al., 2007).

We also tested whether unitary IPSCs display pronounced facilitation in response to paired stimuli, characteristic for mossy fiber transmission (Walker et al., 2001; Safiulina et al., 2006).
However, we observed that unitary IPSCs displayed minimal facilitation (supplemental Fig. 7, available at www.jneurosci. org as supplemental material). We speculated that differences in species (guinea pig or rat was used in previous studies, whereas mice were used in our experiments) might be the reason for the difference.

\section{Application of glutamate to molecular layer induces predominantly excitatory synaptic responses in juvenile and neonatal mice}

Another line of evidence supporting the GABA corelease hypothesis comes from the experiment in which IPSCs are elicited in CA3 pyramidal cells by pressure application of glutamate to the dentate gyrus molecular layer in the presence of AMPA receptor blocker NBQX or DNQX (Walker et al., 2001; Safiulina et al., 2006). In this condition, glutamate is assumed to depolarize granule cell dendrites through activation of NMDA receptors, and not to depolarize axon collaterals coming to the molecular layer. However, wide-spread diffusion from the glutamate-containing pipettes by strong pressure pulses could also activate dendrites or somata of interneurons in the CA3 or the hilar regions, leading to the generation of IPSCs in CA3 pyramidal cells. To attain selective stimulation of granule cells, here we recorded glutamate-evoked responses before application of NBQX, and adjusted the intensity of pressure pulses to evoke the burst appearance of synaptic currents with short latencies. In slices from juvenile mice, short pulse (0.3-0.4 bar, 5-10 ms duration) application of $\mathrm{L}$-glutamate $(100 \mathrm{~mm}$ in pipette, $\mathrm{pH}$ was adjusted to 8.0) to the molecular layer reliably elicited burst appearance of synaptic currents (supplemental Fig. $8 \mathrm{~A}$, available at www.jneurosci.org as supplemental material). These were mostly mediated by glutamate release, because NBQX at $10 \mu \mathrm{M}$ suppressed these responses nearly completely. The residual inward current responses were not increased by glutamate application and blocked by $100 \mu \mathrm{M}$ picrotoxin, suggesting that they reflect spontaneous IPSCs originating from inhibitory inputs other than mossy fibers. In another series of experiments, we confirmed that glutamate selectively activates granule cells in this experimental condition, because the bursts of PSCs were suppressed by DCG-IV, which selectively suppress transmitter release from the mossy fiber terminals (supplemental Fig. 9, available at www.jneurosci.org as supplemental material).

However, glutamate application to the molecular layer elicited some NBQX-resistant burst responses in slices from neonatal mice (supplemental Fig. $8 B$, available at www.jneurosci.org as supplemental material). These are GABAergic IPSCs because picrotoxin abolished the responses. However, delay in NBQXresistant burst of IPSCs was extremely long $(\sim 10 \mathrm{~s}$ in the experiment shown in supplemental Fig. $8 B$, available at www.jneurosci.org as supplemental material). Long delay may reflect spread of glutamate to CA3 or hilar interneurons away from ejection site and/or inadequate positioning of ejection pipettes (Walker et al., 2001). Therefore, we suppose that this find- 
ing does not give confidence to the notion of GABA release from the mossy fiber terminals.

\section{Substantial expression of GAD67 in granule cell layer with low or undetectable levels for GAD65 nor VGAT mRNAs}

As discussed later, expression of key molecules essential for GABA synthesis and release in mossy fibers are controversial in many respects, particularly during the early postnatal period. In the present study, we examined cellular expression and subcellular distribution of GAD, GABA, and VGAT in the developing and adult mouse hippocampus.

First, we performed in situ hybridization analysis for GAD and VGAT mRNAs. Using antisense oligonucleotide probes, gene expression for GAD67, GAD65, and VGAT mRNAs were examined by $\mathrm{x}$-ray film autoradiography (Fig. $6 A-C, G-I)$ and emulsion microautoradiography (Fig. $6 D-F$ ). Their overall expressions in the adult mouse brain were generally similar to each other (Fig. 6A$C)$, and also to those shown in previous reports (Erlander et al., 1991; McIntire et al., 1997). The three mRNAs were highly expressed in the olfactory bulb, olfactory tubercle, septum, reticular thalamic nucleus, and Purkinje cell layer, with moderate levels in various brain regions, such as the caudate-putamen and superior colliculus. In contrast, most other thalamic nuclei lacked expression. Hybridizing signals for GAD67, GAD65, and VGAT mRNAs were sparsely dispersed in the cerebral cortex, Ammon's horn, and hilus of the dentate gyrus (Fig. $6 D-F)$.

In the granule cell layer of the dentate gyrus, homogeneous distribution most likely representing the expression in granule cells was detected for GAD67 mRNA in all sections examined at the adult stage (Fig. 6A,D), whereas no significant signals for GAD65 mRNA were seen there in any sections (Fig. 6B,E). VGAT mRNA in the granule cell layer was detected at low levels in some sections, but below the detection threshold in others (Fig. $6 C, F)$. These adult patterns of gene expression were mostly preserved in neonatal and juvenile mice. At P7, P14, and P21, GAD67 mRNA, but not GAD65 mRNA, was consistently detected in the granule cell layer (Fig. 6G,H), whereas VGAT mRNA was either undetectable or faintly detected (Fig. 6I). It should be noted that, compared with the adult stage (Fig. $\left.6 G_{4}, H_{4}, I_{4}\right)$, no transient upregulation was observed in the granule cell layer of neonatal and juvenile mice for any of the three mRNAs.

The specificity of hybridizing signals were ascertained by virtual disappearance of signals when hybridization was performed in the presence of an excess amount of unlabeled GAD67, GAD65, and VGAT probes, and also by identical patterns of expression with use of two nonoverlapping VGAT
B
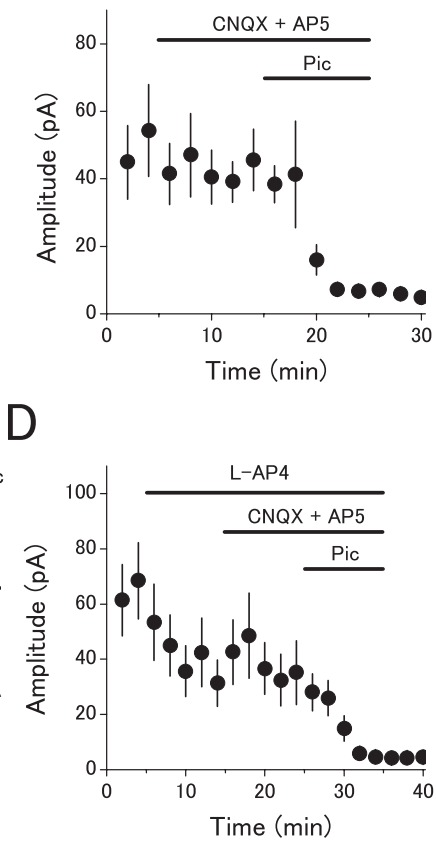

F

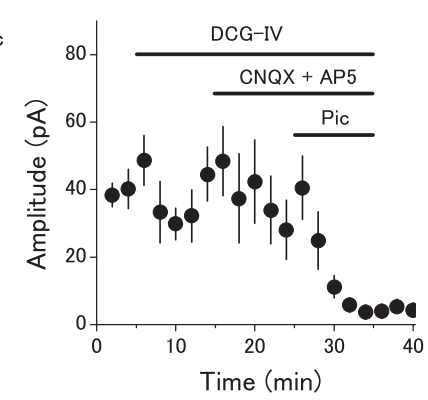

CNQX+AP5+Pic

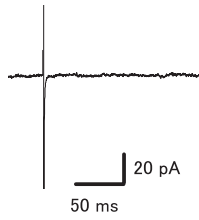

L-AP4

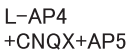

L-AP4

$+\mathrm{CNQX}+\mathrm{AP} 5+\mathrm{PiC}$

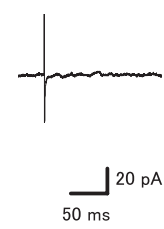

DCG-IV

$+\mathrm{CNQX}+\mathrm{AP} 5+\mathrm{Pi}$

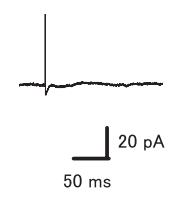

DCG-IV
+ CNQX+AP5

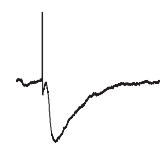

Figure 5. L-AP-4, but not DCG-IV suppresses GABAergic PSCs evoked by minimal stimulation of the granule cell layer in mice (P4-P6). A, Stimulation of just above threshold intensity elicited CNQX and D-AP-5-insensitive, but picrotoxinsensitive PSCs. B, Summary of time course of the PSC amplitude. C, D, Effect of $10 \mu \mathrm{m} \mathrm{L-AP-4,} \mathrm{a} \mathrm{selective} \mathrm{agonist} \mathrm{of} \mathrm{group} \mathrm{III}$ mGluRs, on the minimal stimulation-evoked PSCS. $\boldsymbol{E}, \boldsymbol{F}$, Effect of $1 \mu \mathrm{M}$ DCG-IV, a selective agonist of group II mGluR, on the

probes (data not shown). These results suggest that, of the two GABA synthetic enzymes, GAD67 mRNA is selectively expressed in dentate gyrus granule cells at developing and adult stages, and that VGAT mRNA expression in dentate gyrus granule cells is very low, if any, throughout postnatal stages.

\section{Immunohistochemistry reveals expression of GAD and} GABA, but not of VGAT, in mossy fiber terminals

Then we examined the distribution of GAD, GABA, and VGAT in mossy fiber terminals of neonatal (P5), juvenile (P15) and adult (2 3 months) mice by immunofluorescence with confocal laser-scanning microscopy. The specificity of GAD and VGAT antibodies was confirmed by immunoblot using adult brain extracts (Fig. 7A); the former selectively recognized two bands at $66-67 \mathrm{kDa}$ (i.e., GAD67) and 63-64 $\mathrm{kDa}$ (GAD65), and the latter recognized a single band at 53-55 $\mathrm{kDa}$, as expected. The specificity of immunohistochemistry was shown by spatial patterns of immunolabeling similar to those of their mRNAs, and also by aborted immunolabeling with use of antibodies preabsorbed with antigens (Fig. $7 B$ ). 

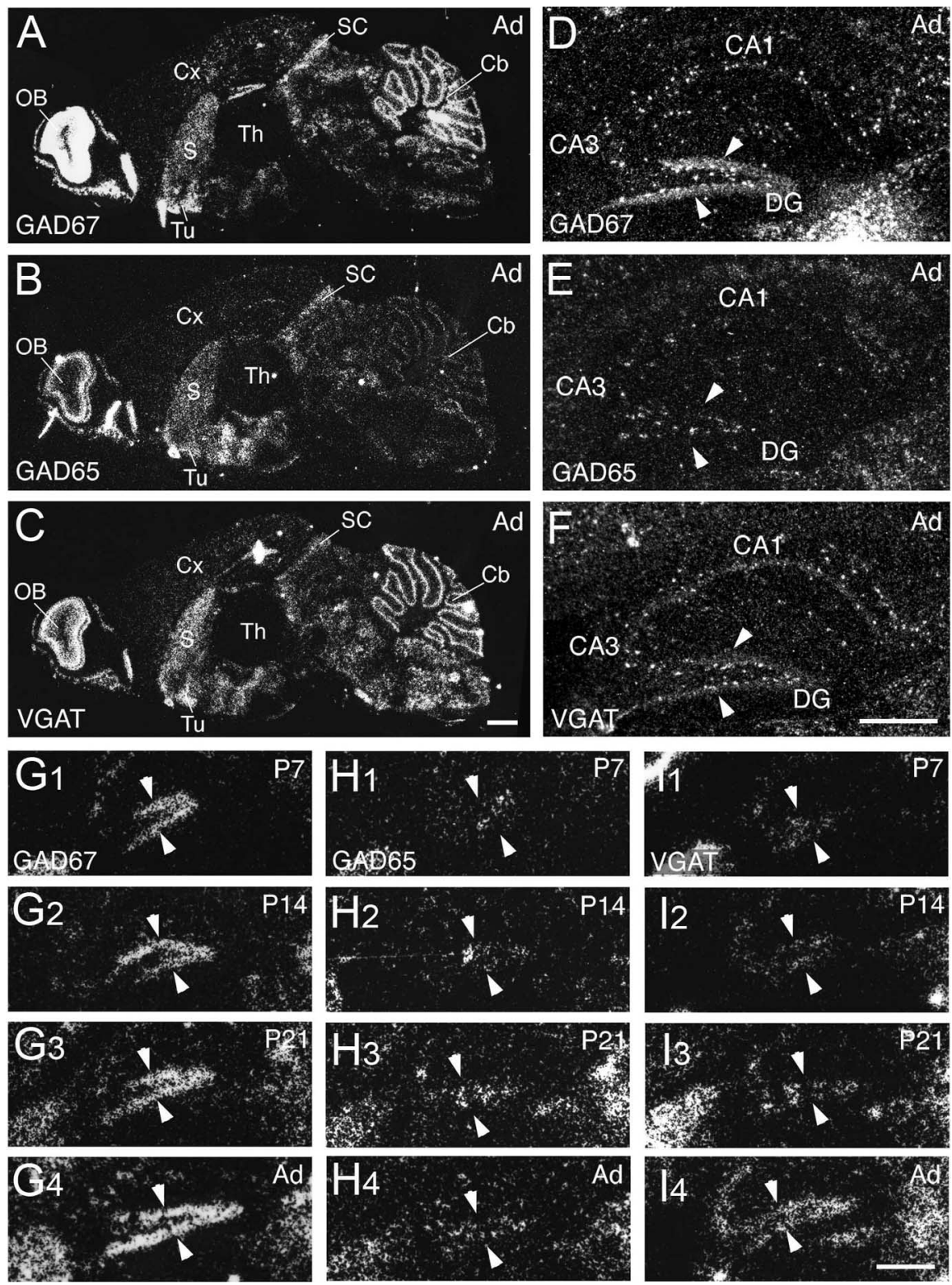

Figure 6. In situ hybridization for GAD67, GAD65, and VGAT mRNAs in the mouse brain. $A-C$, X-ray film autoradiography of parasagittal adult (ad) brain sections. D-F, Enlarged emulsion-dipped microautoradiographic images of the adult hippocampus. G-I, X-ray film autoradiography showing developmental changes in hybridization signals in the hippocampus (P7, P14, P21, and adult). Arrowheads show upper and lower blades of the granule cell layer of the dentate gyrus, respectively. Cx, Cerebral cortex; $\mathrm{Cb}$, cerebellum; SC, superior colliculus; OB, olfactory bulb; $\mathrm{S}$, striatum; Tu, olfactory tubercle; Th, thalamus. Scale bars, $1 \mathrm{~mm}$.

Using these antibodies, we carefully analyzed by double or triple immunofluorescence the stratum lucidum of the CA3 region, in which mossy fiber bundles run and make synaptic contacts with proximal dendrites of CA3 pyramidal cells (Figs. 8, 9).

First, we determined expression of GAD within mossy fiber terminals. At each stage examined, strong labeling for GAD was detected in large puncta (Fig. $8 A-C$ ). They were dispersed in all layers of hippocampal CA3 and almost completely overlapped with VGAT (Fig. 9), indicating that they are terminals of inhibitory interneurons. The neuropil between the inhibitory terminals exhibited weak GAD immunofluorescence (Fig. $8 A-C)$. This weak labeling was restricted to the stratum lucidum, and detected in calbindin-positive/VGluT1-negative tiny irregular structures (nonterminal portion of mossy fibers) (Fig. $8 D-F$ ) and in calbindin-positive/VGluT1positive huge puncta (i.e., terminals of mossy fibers) (Fig. $8 D-F$, arrowheads). In contrast, GAD was not detected in tiny VGluT1-positive tiny puncta in the stratum radiatum, stratum molecularlacunosum, and stratum oriens (Fig. $8 D-F$, arrows), suggesting selective GAD expression in mossy fibers among hippocampal glutamatergic axons. Despite the mossy fiber labeling, no GAD immunoreactivity was seen in granule cell perikarya (data not shown). Therefore, GAD is expressed in terminal and nonterminal portions of mossy fibers from neonatal through adult stages at levels lower than inhibitory terminals.

Then we examined whether GABA was present in mossy fibers (Fig. 8G-I). At each stage examined, intense immunoreactivity for GABA was overlapped with that for GAD (data not shown), indicating high GABA contents in inhibitory terminals. In mossy fiber terminals identified by VGluT1-positive/ calbindin-positive puncta, GABA immunoreactivity was barely seen at P5 (Fig. 8G, arrowheads). At P15 and the adult stage, low immunoreactivity for GABA, which was higher than the background level on capillaries and pyramidal somata, was detected in VGluT1positive/calbindin-positive mossy fiber terminals (arrows) and VGluT1negative/calbindin-positive thin fibers (Fig. $8 H, I$ ). These results suggest that GABA contents are below the detection threshold at P5, and increase thereafter in both terminal and nonterminal portions of mossy fibers.

VGAT is essential for vesicular release by filling GABA into synaptic vesicles (McIntire et al., 1997). Finally, we examined the expression of VGAT in mossy fibers. At each stage examined, strong signals for VGAT were detected in large puncta dispersed in all layers of mouse hippocampal CA3, overlapped almost completely with GAD (Fig. 8), and distributed between calbindin-positive mossy fiber bundles (Fig. 9A-C), suggesting its high contents in terminals of inhibitory interneurons. Different from GAD immunofluorescence, low VGAT immunoreactivities were not observed in the neuropil of the stratum lucidum. To pursue its potential low expression in mossy fibers, we raised the gain level of a confocal laser-scanning microscope (Fig. 9D-I). Faint tiny signals came up in the neuropil between intensely stained inhibitory terminals, and the levels were apparently higher than the background level on capillaries and pyramidal cell somata at all stages examined (Fig. 9D-F). In high-power images, the faint tiny VGAT labeling was detected on VGluT1negative/calbindin-positive mossy fiber bundles (Fig. 9G-I, 
yellow arrowheads). However, even at the high gain levels, VGAT labeling was not discerned in VGluT1-positive/ calbindin-positive mossy fiber terminals in both developing and adult mice. These results suggest that VGAT is translated in low amounts in dentate gyrus granule cells and transported to mossy fibers. However, VGAT seems to be poorly accumulated in, or even excluded from, mossy fiber terminals throughout development, in marked contrast to conventional inhibitory terminals. We observed the same result in the adult rat hippocampus (Fig. 10).

\section{Discussion}

In this study, we re-examined the GABA corelease hypothesis at the hippocampal mossy fiber terminals in young rodents. Against the hypothesis, our electrophysiological and immunohistochemical examinations favor the notion that mossy fiber-CA3 synapses are purely glutamatergic even in young rodents, and that apparent monosynaptic IPSCs, evoked by granule cell layer stimulation, are likely to be elicited by costimulation of an additional inhibitory pathway to CA3 pyramidal cells, as discussed below.

\section{Purely glutamatergic phenotype of mossy fiber terminals in developing and adult mice}

The hypothesis has been proposed that hippocampal mossy terminals corelease excitatory transmitter glutamate and inhibitory transmitter GABA. GABA release from the mossy fiber terminals was observed transiently during early postnatal stages, and disappeared thereafter (Gutièrrez et al., 2003). In this study, however, we found that not only mossy fibers, but also additional GABAergic fibers are recruited by strong stimuli to the granule cell layer, eliciting monosynaptic glutamatergic and GABAergic responses in the CA3 pyramidal cells. However, weak stimuli selectively activate mossy fibers, as assessed by DCG-IV sensitivity, and do not evoke GABAergic responses in juvenile mice. This appears consistent with a previous study that showed that unitary mossy fiber response, recorded by paired recording of dentate gyrus granule cells and CA3 pyramidal cells, does not contain an NBQX-resistant GABAergic component in cultured slices of the rat hippocampus (Mori et al., 2004).

Another line of evidence for GABA release from mossy fiber terminals is based on the finding that minimal stimulation of the granule cell layer elicits picrotoxin-sensitive IPSCs in neonatal rats during the first postnatal week (Safiulina et al., 2006). Because group III mGluR agonist L-AP-4 inhibits the unitary IPSCs, it was suggested that GABA is released from mossy fiber terminals. Although these findings were reproducible in neonatal mice in this study, we found that group II mGluR agonist DCG-IV did not affect the unitary IPSCs. These findings strongly suggest that unitary IPSCs were not originated from mossy fibers, and that inhibitory interneurons are more likely to be a source of GABA release. Mossy fiber synapses in rodents are formed postnatally (Amaral and
Dent, 1981) and the density of synaptic connections, as judged by EPSC amplitude, increases during several weeks after birth (Marchal and Mulle, 2004). Therefore, we speculated that sparse mossy fiber projection in neonatal rodents might readily result in stimulation of inhibitory interneurons by increasing the intensity of stimulation. Our results, however, may be interpreted alternatively assuming that glutamate and GABA release from mossy fibers is differentially regulated by DCG-IV and L-AP-4, as proposed for the adult hippocampus after seizures (Treviño et al., 2007).

We also demonstrated that pressure application of glutamate to the molecular layer elicited predominantly glutamatergic EPSCs. In previous studies, glutamate application was performed only in the presence of NBQX (Walker et al., 2001) or DNQX (Safiulina et al., 2006) to evaluate monosynaptic GABAergic connectivity. In these conditions, it is difficult to estimate how far glutamate diffuses from the tip of the pipette. Our result implies that selective application of glutamate to the granule cell never elicited GABAergic IPSCs in CA3 neurons in juvenile mice. In fact, specimen records in the former study display relatively long delay of several seconds after glutamate pulses (Walker et al., 2001), suggesting that glutamate is spread widely and activates neurons distant from the ejection site. In neonatal rats, bursts of IPSCs appear within $1 \mathrm{~s}$ in the presence of DNQX (Safiulina et al., 2006). However, as discussed by the authors, polysynaptic activation via GABAergic excitation of interneurons cannot be excluded in neonatal animals, because GABA causes depolarization at early developmental stages. Our observation in neonatal mice also attributes to GABA release from group III mGluR agonistsensitive interneurons by polysynaptic activation.

Therefore, all of our electrophysiological results suggest that mossy fibers are glutamatergic not only in the adult hippocampus, but also in neonatal and juvenile hippocampus. 

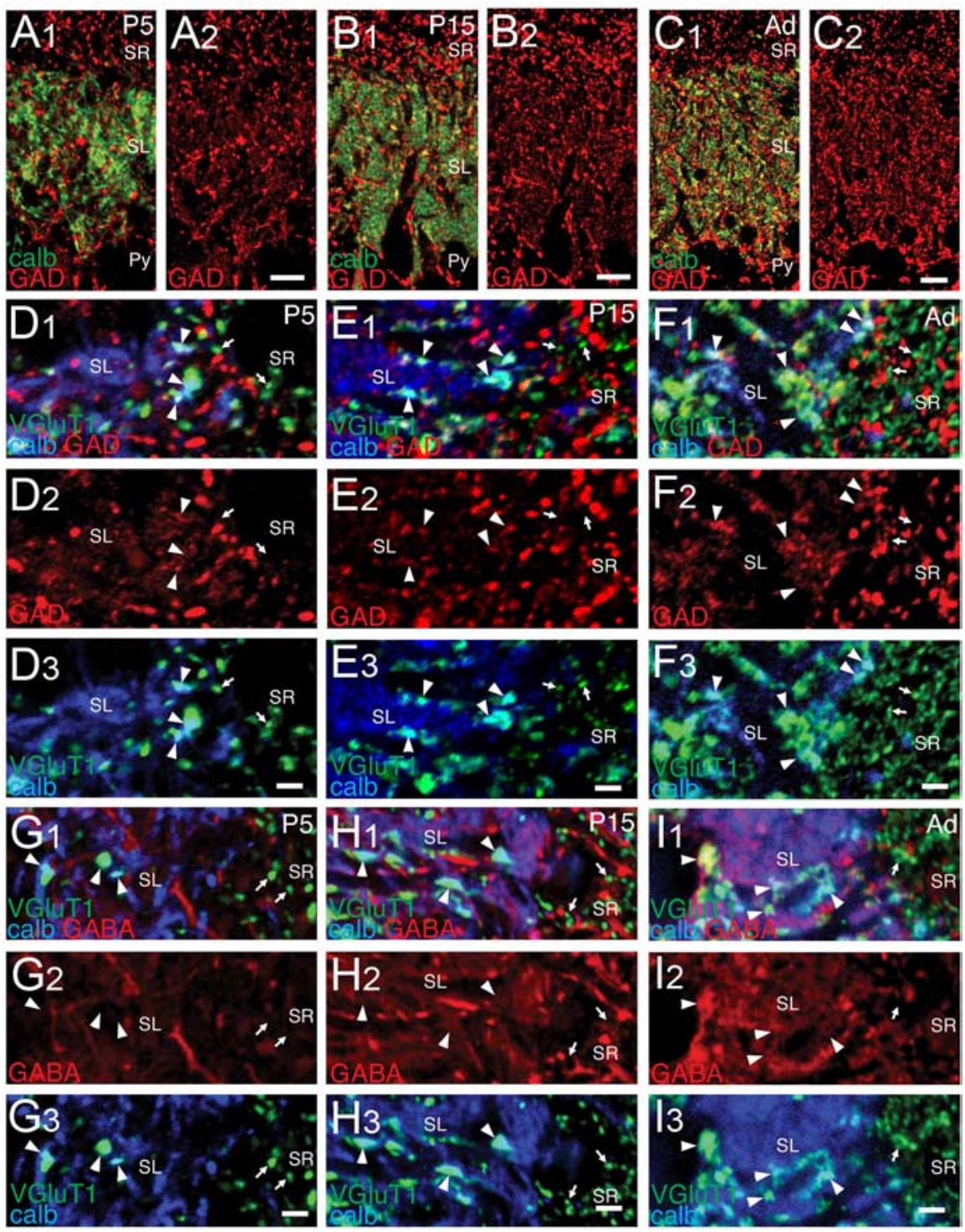

Figure 8. Immunofluorescence showing weak expression of $G A D$ and $G A B A$ within mossy fiber axons and terminals in the $C A 3$ region of the mouse hippocampus. $\boldsymbol{A}-\boldsymbol{C}$, Double immunofluorescence for GAD (red) and calbindin (calb; green) in the strata pyramidale (Py), lucidum (SL), and raditatum (SR) at P5 (A), P15 (B), and adult (ad; $\boldsymbol{C}$. D-F, Triple immunofluorescence for GAD (red) VGluT1 (green) and calbindin (blue). G-I, Triple immunofluorescence for GABA (red) VGluT1 (green) and calbindin (blue). Arrowheads indicate mossy fiber terminals (large puncta expressing both VGluT1 and calbindin). GABA signals are missing in VGluT1-positive terminals in the stratum radiatum (arrows). Scale bars: $A-C, 10 \mu \mathrm{m} ; \mathbf{D}-\mathbf{I}, 5 \mu \mathrm{m}$.

Neuronal source of GABA release for apparent monosynaptic IPSCs

Bulk electrical stimulation of input fibers are often used for electrophysiological studies in slice preparations. The spatial complexity of the actual neuronal network offers the risk of concurrent stimulation of other neurons, and thereby the evoked responses could be contaminated with a variety of additional components. This study argues against the corelease hypothesis, and strongly suggests that hippocampal mossy fibers are purely glutamatergic and that IPSCs elicited by stimulation of the granule cell layer are caused by costimulation of certain interneurons that reside in the CA3 and/or hilar regions and project to CA3 pyramidal cells.

Which kind of inhibitory interneurons are responsible for the apparent monosynaptic GABAergic signaling? It is known that distinct subpopulations of inhibitory interneurons are located in

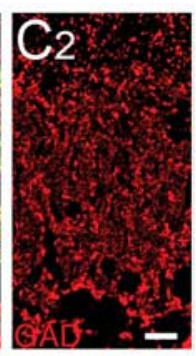

different locations of the CA3 region or dentate gyrus (Spruston et al., 1997; Jinno et al., 1998; Gaiiarsa et al., 2001; Aaron et al., 2003; Jonas et al., 2004). Among them, a subset of interneurons so called mossy fiber-associated (MFA) interneurons resides in the stratum lucidum along the mossy fiber projection, and their axons spread over to the hilus, close to the dentate gyrus granule cell layer (Vida and Frotscher, 2000; Losonczy et al., 2004). MFA interneurons project to and elicit monosynaptic IPSCs in CA3 pyramidal cells. At the moment, we assume that this interneuron is one of the likely candidates for the source of GABA to evoke apparent monosynaptic IPSCs by strong stimulation of the granule cell layer.

Low vesicular filling ability of GABA in mossy fiber terminals of developing and adult mice

Our immunohistochemical observations show that GAD67 mRNA (not GAD65 mRNA) and GAD protein were detectable in hippocampal granule cells or mossy fibers, respectively, throughout developing (the first 3 postnatal weeks) and adult (2-3 months) stages, and that GABA immunoreactivity became detectable at P5 and thereafter. Our observations are consistent at neonatal and juvenile stages, but inconsistent at the adult stage, with the studies by Gutièrrez et al. (Gutièrrez et al., 2003; Maqueda et al., 2003). They have reported that GAD67 and GABA are transiently upregulated during the first three postnatal weeks and disappear in the fourth week. As to the discrepancy, it should be mentioned that mossy fibers have been demonstrated to contain GABA in the adult rat (Sloviter et al., 1996; Bergersen et al., 2003), mouse (Fukuda et al., 1998), monkey (Sandler and Smith, 1991; Sloviter et al., 1996), and human (Sandler and Smith, 1991), and that granule cells and mossy fibers have been shown to express GAD67 mRNA and protein, respectively, in the adult rat (Houser and Esclapez, 1994; Sloviter et al., 1996) and mouse (Fukuda et al., 1998). From the present study and many of these previous studies, it seems safe to conclude that mossy fibers in neonatal, juvenile, and adult hippocampus are provided with GABA synthetic enzyme GAD67, and that GABA accumulates in mossy fibers from the neonatal to juvenile stage and the contents are maintained until at the adult stage.

Expression and distribution of VGAT in mossy fibers are more controversial. It has been reported that VGAT mRNA is expressed in mossy fiber synaptosome-enriched fraction prepared from the adult rat hippocampus (Lamas et al., 2001), and also in microdissected hippocampal granule cell layer of rats at P6, P10, and P5, but not at 2-4 months of age (Gutièrrez et al., 2003). Moreover, VGAT distribution in a subset of mossy fiber terminals has been reported in neonatal rats by its immunofluo- 
rescence colocalization with VGluT1 and zinc transporter 3 (Safiulina et al., 2006). In contrast, it has also been reported that VGAT mRNA is not expressed in normal adult rats and even after kainite-induced seizures (Chaudhry et al., 1998; Sperk et al., 2003). Against this discrepancy, our in situ hybridization detected very faint signals for VGAT mRNA in the granule cell layer in some, but not all, sections. Our immunofluorescence detected faint VGAT immunoreactivity in putative mossy fiber axons only when we substantially raised the gain level of a confocal laser scanning microscope. Even under the condition, VGAT immunoreactivity in the terminal portion of mossy fibers was not detected in developing and adult stages. From the present observations, we assume that mossy fiber terminals, although able to synthesize and store GABA, are poorly provided with molecular machinery for filling GABA into synaptic vesicles. This may explain our electrophysiological data demonstrating that selective stimulation of mossy fibers evoked purely glutamatergic EPSCs in CA3 pyramidal cells, despite the presence of GABA. In future studies, it will be intriguing to test whether or not VGAT is recruited to mossy fiber terminals to release GABA under pathological conditions, because VGAT mRNA has been shown to be upregulated in granule cells by manipulation evoking hyperexcitability in adulthood (Gomez-Lira et al., 2005).

In summary, despite careful and combinatorial examination by electrophysiological and histochemical approaches, we did not find any clear evidence for GABA release from the glutamatergic mossy fiber terminals in the developing mouse hippocampus. Rather, all of the results in this study support that mossy fibers are purely glutamatergic and that apparent monosynaptic IPSC is evoked by costimulation of the inhibitory interneurons in the CA3 and/or hilar regions through an axon reflex mechanism.

\section{References}

Aaron GB, Wilcox KS, Dichter MA (2003) Different patterns of synaptic transmission revealed between hippocampal CA3 stratum oriens and stratum lucidum interneurons and their pyramidal cell targets. Neuroscience 117:169-181.

Alle H, Geiger JR (2007) GABAergic spill-over transmission onto hippocampal mossy fiber boutons. J Neurosci 27:942-950.

Amaral DG, Dent JA (1981) Development of the mossy fibers of the dentate gyrus: 1. A light and electron-microscopic study of the mossy fibers and their expansions. J Comp Neurol 195:51-86.

Bergersen L, Ruiz A, Bjaalie JG, Kullmann DM, Gundersen V (2003) GABA and $\mathrm{GABA}_{\mathrm{A}}$ receptors at hippocampal mossy fibre synapses. Eur J Neurosci 18:931-941.

Chaudhry FA, Reimer RJ, Bellocchio EE, Danbolt NC, Osen KK, Edwards RH, Storm-Mathisen J (1998) The vesicular GABA transporter, VGAT, lo-


Immunofluorescence showing the lack of VGAT expression in hippocampal mossy fiber terminals throughout postG-I, Enlarged images of triple immunofluorescence for VGAT (red) VGluT1 (green) and calbindin (blue) indicate mossy fiber axons, which are labeled faintly for VGAT, intensely for calbindin, and negatively for VGluT1. Scale bars: $\boldsymbol{A}-\boldsymbol{F}, 10 \mu \mathrm{m} ; \boldsymbol{E}-\boldsymbol{I}, 5 \mu \mathrm{m}$.

calizes to synaptic vesicles in sets of glycinergic as well as GABAergic neurons. J Neurosci 18:9733-9750.

Erlander MG, Tillakaratne NJK, Feldblum S, Patel N, Tobin AJ (1991) Two genes encode distinct glutamate decarboxylases. Neuron 7:91-100.

Fukuda T, Aika Y, Heizmann CW, Kosaka T (1998) GABAergic axon terminals at perisomatic and dendritic inhibitory sites show different immunoreactivities against two GAD isoforms, GAD67 and GAD65, in the mouse hippocampus: a digitized quantitative analysis. J Comp Neurol 395:177-194.

Gaïarsa JL, Khalilov I, Gozlan H, Ben-Ari Y (2001) Morphology of CA3 non-pyramidal cells in the developing rat hippocampus. Dev Brain Res 127:157-164.

Geiger JR, Bischofberger J, Vida I, Frobe U, Pfitzinger S, Weber HJ, Haverkampf K, Jonas P (2002) Patch-clamp recording in brain slices with improved slicer technology. Pflügers Arch 443:491-501.

Gómez-Lira G, Lamas M, Romo-Parra H, Gutiérrez R (2005) Programmed and induced phenotype of the hippocampal granule cells. J Neurosci 25:6939-6946.

Gutiérrez R (2000) Seizures induce simultaneous GABAergic and glutama- 

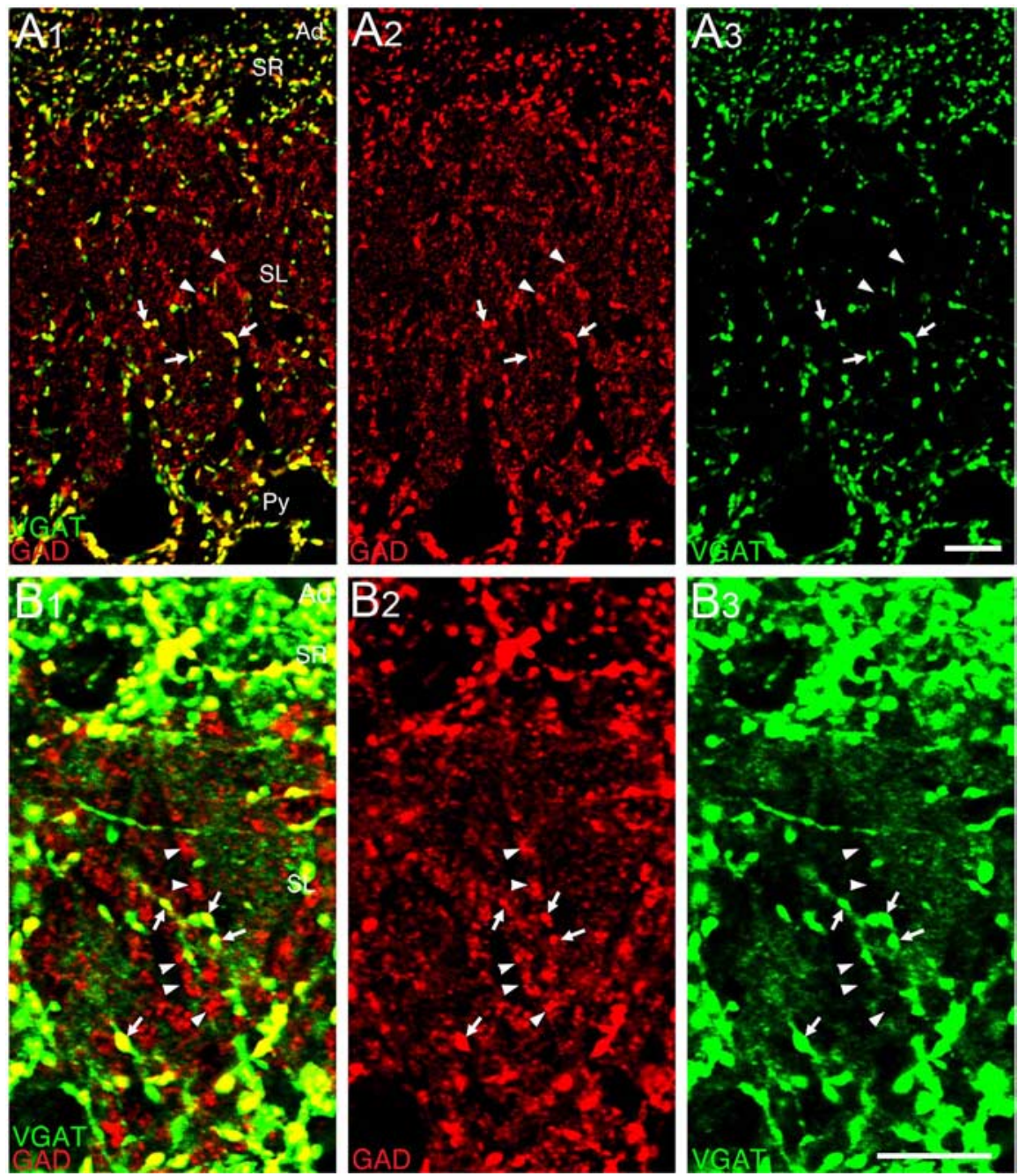

Figure 10. $A, B$, Double immunofluorescence for VGAT (green) and $G A D$ (red) in the CA3 region of adult rat hippocampus at the normal $(\boldsymbol{A})$ and raised $(\boldsymbol{B})$ gain levels for VGAT. In both settings, intense VGAT and GAD are colocalized on inhibitory terminals (arrows), which are dispersed in all hippocampal layer layers. Under the normal gain level $(\boldsymbol{A})$, weak GAD labeling on putative mossy fibers in the stratum lucidum (SL) appears to lack VGAT immunoreactivity (arrowheads). $\boldsymbol{B}$, At a much higher gain level, enlarged images demonstrate that weak immunoreactivities for GAD and VGAT are both distributed over the region occupied by mossy fiber bundles, but their fine distribution seems to be nonoverlapping. See definitions of abbreviations in Figure 8 . Scale bars, $10 \mu \mathrm{m}$.

tergic transmission in the dentate gyrus-CA3 system. J Neurophysiol 84:3088-3090.

Gutiérrez R (2002) Activity-dependent expression of simultaneous glutamatergic and GABAergic neurotransmission from the mossy fibers in vitro. J Neurophysiol 87:2562-2570.

Gutiérrez R (2005) The dual glutamatergic-GABAergic phenotype of hippocampal granule cells. Trends Neurosci 28:297-303.

Gutiérrez R, Heinemann U (2001) Kindling induces transient fast inhibition in the dentate gyrus-CA3 projection. Eur J Neurosci 13:1371-1379.

Gutiérrez R, Romo-Parra H, Maqueda J, Vivar C, Ramirez M, Morales MA, Lamas M (2003) Plasticity of the GABAergic phenotype of the "glutamatergic" granule cells of the rat dentate gyrus. J Neurosci 23:5594-5598.

Houser CR, Esclapez M (1994) Localization of mRNAs encoding two forms of glutamic acid decarboxylase in the rat hippocampal formation. Hippocampus 4:530-545.

Jinno S, Aika Y, Fukuda T, Kosaka T (1998) Quantitative analysis of GABAergic neurons in the mouse hippocampus, with optical disector using confocal laser scanning microscope. Brain Res 814:55-70.

Jonas P, Bischofberger J, Sandkuhler J (1998) Corelease of two fast neurotransmitters at a central synapse. Science 281:419-424.
Jonas P, Bischofberger J, Fricker D, Miles R (2004) Interneuron diversity series: fast in, fast out - temporal and spatial signal processing in hippocampal interneurons. Trends Neurosci 27:30-40.

Kamiya H, Shinozaki H, Yamamoto C (1996) Activation of metabotropic glutamate receptor type $2 / 3$ suppresses transmission at rat hippocampal mossy fibre synapses. J Physiol (Lond) 493:447-455.

Kamiya H, Umeda K, Ozawa S, Manabe T (2002) Presynaptic $\mathrm{Ca}^{2+}$ entry is unchanged during hippocampal mossy fiber long-term potentiation. J Neurosci 22:10524-10528.

Lamas M, Gomez-Lira G, Gutiérrez R (2001) Vesicular GABA transporter mRNA expression in the dentate gyrus and in mossy fiber synaptosomes. Mol Brain Res 93:209-214.

Losonczy A, Biro AA, Nusser Z (2004) Persistently active cannabinoid receptors mute a subpopulation of hippocampal interneurons. Proc Natl Acad Sci USA 101:1362-1367.

Maqueda J, Ramirez M, Lamas M, Gutiérrez R (2003) Glutamic acid decarboxylase (GAD) ${ }_{67}$ but not $\mathrm{GAD}_{65}$, is constitutively expressed during development and transiently overexpressed by activity in the granule cells of the rat. Neurosci Lett 353:69-71.

Marchal C, Mulle C (2004) Postnatal maturation of mossy fibre excitatory transmission in mouse CA3 pyramidal cells: a potential role for kainate receptors. J Physiol (Lond) 561:27-37.

McIntire SL, Reimer RJ, Schuske K, Edwards RH, Jorgensen EM (1997) Identification and characterization of the vesicular GABA transporter. Nature 389:870-876.

Miura E, Fukaya M, Sato T, Sugihara K, Asano M, Yoshioka K, Watanabe M (2006) Expression and distribution of JNK/SAPKassociated scaffold protein JSAP1 in developing and adult mouse brain. J Neurochem 97:1431-1446.

Miyazaki T, Fukaya M, Shimizu H, Watanabe M (2003) Subtype switching of vesicular glutamate transporters at parallel fibre-Purkinje cell synapses in developing mouse cerebellum. Eur J Neurosci 17:2563-2572.

Mori M, Abegg MH, Gahwiler BH, Gerber U (2004) A frequency-dependent switch from inhibition to excitation in a hippocampal unitary circuit. Nature 431:453-456.

Nabekura J, Katsurabayashi S, Kakazu Y, Shibata S, Matsubara A, Jinno S, Mizoguchi Y, Sasaki A, Ishibashi H (2004) Developmental switch from GABA to glycine release in single central synaptic terminals. Nat Neurosci 7:17-23.

Nakagawa S, Watanabe M, Inoue Y (1996) Regional variation in expression of calbindin and inositol 1,4,5-trisphosphate receptor type 1 mRNAs in the cerebellum of the Staggerer mutant mouse. Eur J Neurosci 8:1401-1407.

Pelkey KA, Tropolnik L, Lacaille JC, McBain CJ (2006) Compartmentalized $\mathrm{Ca}^{2+}$ channel regulation at divergent mossy-fiber release sites underlies target cell-dependent plasticity. Neuron 52:497-510.

Represa A, Ben-Ari Y (2005) Trophic actions of GABA on neuronal development. Trends Neurosci 28:278-283.

Ruiz A, Fabian-Fine R, Scott R, Walker MC, Rusakov DA, Kullmann DM (2003) $\mathrm{GABA}_{\mathrm{A}}$ receptors at hippocampal mossy fibers. Neuron 39:961-973.

Safiulina VF, Fattorini G, Conti F, Cherubini E (2006) GABAergic signaling at mossy fiber synapses in neonatal rat hippocampus. J Neurosci 26:597-608. 
Sandler R, Smith AD (1991) Coexistence of GABA and glutamate in mossy fiber terminals of the primate hippocampus: an ultrastructural study. J Comp Neurol 303:177-192.

Sloviter RS, Dichter MA, Rachinsky TL, Dean E, Goodman JH, Sollas AL, Martin DL (1996) Basal expression and induction of glutamate decarboxylase and GABA in excitatory granule cells of the rat and monkey hippocampal dentate gyrus. J Comp Neurol 373:593-618.

Sperk G, Schwarzer C, Heilman J, Furtinger S, Reimer RJ, Edwards RH, Nelson N (2003) Expression of plasma membrane GABA transporters but not of the vesicular GABA transporter in dentate granule cells after kainic acid seizures. Hippocampus 13:806-815.

Spruston N, Lubke J, Frotscher M (1997) Interneurons in the stratum lucidum of the rat hippocampus: an anatomical and electrophysiological characterization. J Comp Neurol 385:427-440.

Treviño M, Vivar C, Gutièrrez R (2007) $\beta / \gamma$ Oscillatory activity in the CA3 hippocampal area is depressed by aberrant GABAergic transmission from the dentate gyrus after seizures. J Neurosci 27:251-259.
Vida I, Frotscher M (2000) A hippocampal interneuron associated with the mossy fiber system. Proc Natl Acad Sci USA 97:1275-1280.

Vogt KE, Nicoll RA (1999) Glutamate and gamma-aminobutyric acid mediate a heterosynaptic depression at mossy fiber synapses in the hippocampus. Proc Natl Acad Sci USA 96:1118-1122.

Walker MC, Ruiz A, Kullmann DM (2001) Monosynaptic GABAergic signaling from dentate to CA3 with a pharmacological and physiological profile typical of mossy fiber synapses. Neuron 29:703-715.

Yamada K, Fukaya M, Shimizu H, Sakimura K, Watanabe M (2001) NMDA receptor subunits GluRe1, GluR $\varepsilon 3$ and GluR $\zeta 1$ are enriched at the mossy fibre-granule cell synapse in the adult mouse cerebellum. Eur J Neurosci 13:2025-2036.

Yokoi M, Kobayashi K, Manabe T, Takahashi T, Sakaguchi I, Katsuura G, Shigemoto R, Ohishi H, Nomura S, Nakamura K, Nakao K, Katsuki M, Nakanishi S (1996) Impairment of hippocampal mossy fiber LTD in mice lacking mGluR2. Science 273:645-647. 